Neurosurg Focus 20 (2):E5, 2006

\title{
Cervical spine trauma in children: a review
}

\author{
Todd McCall, M.D., Dan Fassett, M.D., and Douglas Brockmeyer, M.D. \\ Department of Neurosurgery, Primary Children's Medical Center, University of Utah, \\ Salt Lake City, Utah
}

\begin{abstract}
$\checkmark$ Injuries of the cervical spine are relatively rare in children but are a distinct clinical entity compared with those found in adults. The unique biomechanics of the pediatric cervical spine lead to a different distribution of injuries and distinct radiographic features. Children younger than 9 years of age usually have upper cervical injuries, whereas older children, whose biomechanics more closely resemble those of adults, are prone to lower cervical injuries. Pediatric cervical injuries are more frequently ligamentous in nature, and children are also more prone to spinal cord injury without radiographic abnormality than adults are. Physial injuries are specific only to children. Radiographically benign findings, such as pseudosubluxation and synchondrosis, can be mistaken for traumatic injuries. External immobilization with a halo brace can be difficult and is associated with a high complication rate because of the thin calvaria in children. Surgical options have improved with the development of instrumentation specifically for children, but special considerations exist, such as the small size and growth potential of the pediatric spine.
\end{abstract}

KEY WoRDS - cervical spine • trauma - pediatric neurosurgery

$\mathrm{T}$ HE treatment of cervical spine injuries in children must be founded on an understanding of spine development. Differences in injury patterns, interpretation of radiographic studies, and management of injuries are a direct result of the unique anthropometrics and biomechanics of a child. Historically, literature specifically addressing cervical spine injuries in children has been scarce; most studies have been focused on adults. In more recent years, as distinct aspects of the pediatric spine have been better appreciated, more attention has been given exclusively to injuries of the cervical spine in younger patients.

Besides incomplete knowledge regarding pediatric cervical injuries, other challenges exist in the management of these childhood traumas, such as the difficulty in obtaining a complete history from the patient and the unsuitability of some medical devices or surgical hardware for very young patients. Despite these obstacles, a logical and systematic diagnostic and treatment paradigm can be applied to the pediatric patient with a potential cervical injury. The purpose of this article is to highlight the differences between the adult and pediatric cervical spine, and to detail how these differences affect the diagnosis and treatment of traumatic injuries.

\section{Causes of SCI}

Injuries of the cervical spine ${ }^{19,64}$ and spinal $\operatorname{cord}^{28,48,78}$ in

Abbreviations used in this paper: $\mathrm{AP}=$ anteroposterior; $\mathrm{CT}=$ computerized tomography; MR = magnetic resonance; NEXUS = National Emergency X-Radiography Utilization Study; SCI = spinal cord injury; SCIWORA = SCI without radiographic abnormality; VB = vertebral body. children are relatively infrequent compared with their occurrence in adults. Pediatric cases of cervical spine injury account for less than $10 \%$ of all such injuries, ${ }^{50}$ and approximately 40 to $60 \%$ of all pediatric spine injuries occur in the cervical region. ${ }^{40,41}$ Besides the ones associated with birth trauma, young children rarely incur fractures below C-2. ${ }^{40,80}$ As children become older and their biomechanics more closely approximate those of adults, however, fractures more commonly occur in the lower cervical spine. ${ }^{40}$

Motor vehicle accidents are the most common cause of pediatric cervical injuries, but obstetrical complications, falls, sports, diving accidents, firearms, and child abuse ac-

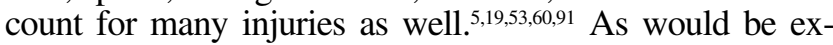
pected, the contribution of different mechanisms varies with the patient's age. In neonates, the leading cause of cervical injury is obstetrical complications. ${ }^{91,96}$ Spinal cord injuries occur in one of 60,000 births, ${ }^{100}$ with the upper cervical region most frequently involved. ${ }^{59} \mathrm{Cardinal}$ features of birthrelated upper cervical SCI include apnea, flaccid quadriplegia, and injuries due to the use of forceps. Unfortunately, neonatal death is common with such injuries. ${ }^{1,3}$ Birth-related cervical injuries are usually associated with a breech presentation, ${ }^{12,15}$ although they can also occur with cephalic delivery ${ }^{87}$ Cervical injuries in infants and toddlers usually result from falls, motor vehicle accidents, and nonaccidental trauma. ${ }^{37,38,93}$ Among children 3 to 10 years of age, falls, bicycle mishaps, and auto-pedestrian accidents account for most injuries, ${ }^{4,80}$ and after the age of 10 years, sports and motor vehicle accidents are the biggest culprits..$^{40,52,53}$

\section{Anatomy and Biomechanics}

The unique anatomy and biomechanics of the pediatric 
cervical spine help explain the different radiographic features, injury patterns, and management options found in children compared with those in adults. The principal difference is that the pediatric cervical spine is intrinsically more elastic compared with that of adults, especially in the first 8 years of life..$^{43}$ In a study of neonatal cadavers, the vertebral column could stretch as much as 2 in without disruption, but the spinal cord could only stretch 0.25 in. ${ }^{58}$ This elasticity is a result of several distinct features of the pediatric cervical spine. First, the facet joints are more shallow than in the adult spine and are oriented horizontally. ${ }^{20,97}$ This has the effect of increasing translational mobility and movement during flexion and extension. Second, spinal ligaments and joint capsules can withstand significant stretching without tearing, which contributes to the occurrence of pseudosubluxation. ${ }^{32,92,97}$ Third, several authors have argued that the anterior wedging of the VBs allows ventral slippage between motion segments, ${ }^{32,92}$ although others have noted that the wedging that appears on radiographs is due to a ring apophysis that does not ossify before the age of 12 years, and that therefore this is merely a radiographic and not an anatomical finding. ${ }^{33,57}$ Finally, absent uncinate processes and weak nuchal muscles also lend more flexibility to the spine. ${ }^{7,97}$

Another important feature in children younger than 8 years of age is the relatively large head compared with the body. The added weight shifts the fulcrum of movement to the upper cervical spine, with the greatest movement at C2-3 in infants and young children., ${ }^{8,14,92,97,105}$ By 5 to 6 years of age, the fulcrum shifts to $\mathrm{C} 3-4$, and in adolescents and young adults the level of maximal flexion is C5-6, the same as in mature adults. This disparity in the fulcrum of movement explains why the majority of cervical spine injuries occur between the occiput and C-2 in children younger than 9 years of age, whereas the distribution of cervical injuries in children older than 9 years is similar to that in adults, with fractures and fracture-dislocations predominantly occurring in the lower cervical spine. . $^{30,40,41}$

A large head relative to the body has one other critical consequence, which is to force the cervical spine into kyphosis when a child is placed on a firm backboard. In the setting of trauma, this may exacerbate a traumatic kyphotic deformity and compromise neurological function. ${ }^{46}$ In a study of 40 children, all patients required torso elevation (mean elevation $25 \mathrm{~mm}$ ) to rest the neck in a neutral position ${ }^{66}$ Semirigid cervical collars are not adequate to prevent flexion, and therefore the torso needs to be raised or a recess for the occiput is required..$^{49,98}$

\section{Clinical Presentation}

The possible presenting symptoms of a child with cervical spine trauma are highly variable. This type of trauma or SCI should be suspected if unconsciousness, torticollis, cervical rigidity, muscle guarding, neck pain, radicular pain, numbness, or history of transient or fixed neurological deficits is present. The most common symptom is pain, accompanied most frequently by focal midline tenderness. A stiff neck is often present and can impair adequate flexion and extension on radiographic studies. Pain that does not resolve within the first 1 or 2 weeks despite initially normal results on radiographs should raise concern that an injury has been overlooked and should be investigated further. Weakness and sensory changes, along with pain, may be radicular or myelopathic in nature. Autonomic disturbances are less common and can include bowel and bladder dysfunction. In the setting of acute trauma, hypotension without tachycardia should raise concern for severe SCI. ${ }^{13}$

Children are less likely than adults to suffer neurological injury with cervical spine trauma, although when neurological injury does ensue it often occurs with fracturedislocations ${ }^{40,48}$ Facet dislocations are also associated with neurological sequelae. Bilateral dislocated facets generally affect the spinal cord, whereas a unilateral facet injury generally damages a nerve root. Injuries are often incomplete and some improvement can be expected, even late in the course of recovery. ${ }^{40,80}$ Unfortunately, patients with complete SCIs normally do not recover. ${ }^{18,44,62,75}$ Delayed progression of neurological deficits can also develop if initial instability is not discovered, which is more often a risk in cases of multiple trauma. ${ }^{75,107}$

\section{Neuroimaging Studies}

\section{Plain Radiographs}

Multiple studies have been conducted in an attempt to stratify pediatric patients into low- and high-risk groups and to try to identify which patients require static cervical spine x-ray films (AP and lateral) to evaluate for traumatic injury. Laham, et al., ${ }^{55}$ defined low-risk patients as those who were able to communicate verbally and had no cervical discomfort. Of the 135 children at low risk who were studied retrospectively, no cases of cervical spine injury were diagnosed using plain $\mathrm{x}$-ray films.

More recently, a prospective multicenter trial was conducted to evaluate the NEXUS decision instrument for identifying pediatric patients who have suffered blunt trauma and in whom radiographs of the cervical spine should be obtained. ${ }^{99}$ Low-risk patients must meet all five NEXUS criteria, which are as follows: 1) absence of midline cervical tenderness; 2) no evidence of intoxication; 3) normal level of alertness; 4) normal results on neurological examination; and 5) absence of a painful or distracting injury. If a patient fulfills all five of the NEXUS criteria, plain radiographs are of marginal value. None of the 603 children designated as low-risk had evidence of cervical spine trauma on plain X-ray films. Of note, approximately $1 \%$ of patients who did not meet all of the NEXUS criteria had a cervical spine injury. Most patients for whom a trauma response is activated do not meet all of the NEXUS criteria acutely, and therefore at our institution we initially obtain anterolateral and posterior x-ray films as a component of the trauma protocol in all of these patients.

The usefulness of an odontoid view in very young children is questionable. In a retrospective review, 10 patients younger than 9 years of age who had sustained a cervical spine injury between the occiput and C-3 were identified, but in none of these cases was the diagnosis based on a transoral odontoid plain X-ray film. ${ }^{17}$ In another study that was based on a questionnaire, investigators suggested that children younger than 5 years of age do not require a transoral x-ray film as part of a trauma protocol. ${ }^{95}$ At our institution, in children 5 years of age or younger we obtain only $\mathrm{AP}$ and lateral plain $\mathrm{x}$-ray films when the trauma protocol 
has been activated, whereas children older than 5 years also undergo a transoral view.

Flexion and extension radiographs are still the gold standard for evaluating instability of the cervical spine. If a patient does not meet the NEXUS criteria but has normal results on AP and lateral views, then flexion and extension views are indicated to evaluate stability. Dynamic x-ray films should be obtained only if the patient is neurologically intact. Otherwise, MR imaging should be considered for further evaluation. The authors of some studies suggest that if results of AP and lateral x-ray films are normal, however, then the value of dynamic films is disputable..$^{29,77}$ Dynamic views are often unsatisfactory initially because of muscle spasms, and in these cases the studies must be repeated once the spasm has resolved.

\section{Usefulness of CT Scans}

For children younger than 10 years of age, the benefit of $\mathrm{CT}$ scans for diagnosing cervical injuries is limited because most of these types of injuries in this age group are ligamentous, with no osseous component. ${ }^{26,41}$ Even in children older than 10 years, $20 \%$ of cervical injuries will be ligamentous and will not involve a fracture. ${ }^{31,99}$ Therefore, normal anatomical findings on a CT scan cannot be used to exclude a cervical injury in children and should not be used exclusively for cervical spine clearance. ${ }^{81}$ Still, CT scans are superior to radiographs for defining bone anatomy and are a useful adjunct to other imaging modalities for presurgical planning.

\section{Usefulness of MR Imaging}

An MR imaging session can provide several useful functions in the setting of pediatric cervical spine trauma. First, MR imaging can be used to clear the cervical spine of a child if initial plain x-ray films show normal results but the child is obtunded, intubated, or uncooperative. ${ }^{35}$ Also, if results on plain x-ray films or CT scans are equivocal, an MR image can also be used to clear the cervical spine. Second, if a child has persistent or delayed neurological symptoms with normal findings on x-ray films and a CT scan, an MR imaging study may reveal soft-tissue, ligamentous, or disc injury that would otherwise remain unrecognized. In one study of 52 pediatric patients with trauma, $31 \%$ had significant MR imaging findings, and in four of these children the results of MR imaging directly influenced the surgical management. ${ }^{51}$ Finally, in cases of SCI, MR imaging can provide useful prognostic information. ${ }^{23}$

\section{Pitfalls of Neuroimaging in Pediatric Patients}

The radiographic appearance of the cervical spine in children differs in several ways from that of adults, and to further complicate matters, these differences change with age. As a result, pediatric cervical spine injuries can often have a delayed or inaccurate diagnosis. In a retrospective review of 37 trauma cases, a misdiagnosis was identified in $24 \%$ of cases involving children younger than 9 years of age and in $15 \%$ of cases in which the child was 9 years of age or older. ${ }^{6}$

Pseudosubluxation in the upper cervical spine of children is considered a normal finding. ${ }^{74,86}$ To determine the incidence of pseudosubluxation, Cattell and Filtzer ${ }^{20}$ evaluated 160 pediatric patients ranging from 1 to 16 years of age.
They found that among children younger than 8 years, at least $3 \mathrm{~mm}$ of anterior displacement was present in $40 \%$ at C2-3, and in $14 \%$ of children it was present at C3-4. In pediatric patients with trauma, pseudosubluxation is not associated with intubation, injury severity, or outcome, from which we infer that pseudosubluxation is an incidental finding in these cases. ${ }^{84}$ The only variable that correlates with pseudosubluxation appears to be age; this condition occurs in children up to 14 years of age. Shaw and colleagues ${ }^{84}$ have provided strict criteria for determining the presence of pseudosubluxation. A line drawn through the posterior arches of C-1 and C-3 should touch, pass through, or lie within $1 \mathrm{~mm}$ anterior to the anterior cortex of the posterior arch of $\mathrm{C}-2$. If none of these conditions is met, then true dislocation should be suspected.

A second common feature of the pediatric spine that can be misleading is the collection of synchondroses in all cervical vertebrae. The $\mathrm{C}-2$ vertebra, which is especially prone to injury in these young children, has a total of three synchondroses between the dens, body, and arch, which usually close between the ages of 3 and 7 years. ${ }^{7,94}$ Of these three synchondroses, the dens-arch one is most pronounced and is therefore most frequently mistaken for a fracture. A key feature that distinguishes the dens-arch synchondrosis from a true fracture is that the synchondrosis is visible on an oblique but not on a straight lateral x-ray film. Subaxial vertebrae in young children will have synchondroses between the posterior and anterior elements, which can be mistaken for fractures.

Other radiographic features that may be misread as evidence of cervical spine injury include a lack of cervical lordosis and notable angulation at individual intervertebral spaces. ${ }^{20,92}$ Pronounced vascular channels in the ossification center can be misconstrued as fractures. ${ }^{43}$

\section{Evaluating Cervical Stability}

Several methods have been developed to determine cervical spine stability. Some rely on objective measurements, whereas others are more descriptive. No individual method is definitive, but they all have value in that they provide a systematic approach to this difficult and often confusing clinical dilemma.

In a study of adult cadavers performed by White and colleagues, ${ }^{103}$ when all ligaments were intact the horizontal motion of one VB on the next did not exceed $3.5 \mathrm{~mm}$ and the angular displacement of one VB on another did not exceed $11^{\circ}$. These results became the basis for the well-accepted radiographic criteria of cervical instability proposed by White and Panjabi. ${ }^{104}$ Specifically, cervical spine instability should be considered when a static lateral x-ray film demonstrates sagittal plane displacement of greater than $3.5 \mathrm{~mm}$ or relative plane angulation of greater than $11^{\circ}$ in the setting of acute trauma. In one series, ${ }^{105}$ however, investigators identified eight patients with occult cervical ligamentous instability and ages ranging from 18 to 23 years who did not meet the criteria of White and Panjabi for instability.

Applying the criteria of White and Panjabi to the pediatric spine is problematic because increased elasticity due to factors discussed previously allows for more recoil of the spine after injury. The increased recoil helps restore align- 
ment to the cervical spine following injury, and therefore the upper limit of acceptable angulation in children needs to be lower than that in adults. Currently, angulation greater than $7^{\circ}$ is considered a sign of ligamentous injury in the pediatric cervical spine. ${ }^{102}$ Furthermore, $3.5 \mathrm{~mm}$ of subluxation in children may be physiological, based on studies describing pseudosubluxation. ${ }^{20}$ Therefore, if a child is younger than 8 years of age, cervical instability should be considered if more than $4.5 \mathrm{~mm}$ of subluxation is present at $\mathrm{C} 2-3$ or C3-4, and greater than $3.5 \mathrm{~mm}$ of subluxation should not be tolerated at any level in patients older than 8 years of age. ${ }^{71}$

Another paradigm for evaluating the spine is the twocolumn model, in which the cervical spine is divided into anterior and posterior columns. .7,79 $^{4}$ The anterior column consists of the anterior longitudinal ligament, VB, posterior longitudinal ligament, anterior and posterior portions of the anulus fibrosus, and the intertransverse ligaments. The posterior column includes the pedicles, laminae, transverse processes, spinous process, interspinous ligaments, supraspinous ligaments, ligamentum flavum, and capsular ligaments. In adults, the spine remains stable under physiological loads if all of the anterior and one posterior element or all of the posterior and one anterior element are intact. ${ }^{73,103}$ A three-column model has also been proposed, but it was developed in a retrospective review of thoracolumbar injuries and does not provide much added benefit for clinical decisions regarding the cervical spine. ${ }^{25}$ The two-column model fits nicely with the binary option of surgical approaches, these being either anterior or posterior.

Spine stability may also be considered with respect to the type of cervical injury. Anterior wedge compression fractures are usually stable, although greater than $15^{\circ}$ of VB angulation should be considered a sign of instability. Teardrop fractures can be unstable, depending on the severity of injury to the disc, facet joints, and anterior and posterior ligaments. ${ }^{42}$ Unilateral or bilateral locked facets, burst fractures, and fracture-dislocations are unstable, and ligamentous injury without an associated fracture may be either stable or unstable.

Physial injuries are specific to young children, occurring when the vertebral endplate is separated from the body through the epiphysis. Autopsy findings in $12 \%$ of juvenile trauma cases revealed a physial injury, most commonly involving the inferior endplate. ${ }^{5}$ Salter-Harris Type I injuries (in which the epiphysis is intact but separated from the metaphysis) are very unstable, require surgical stabilization, and are seen in infants and young children. Type III injuries (in which the fracture traverses the epiphysis and extends into the epiphysial plate), which may be treated with immobilization, are associated with older adolescents. ${ }^{56,67}$ These injuries can be difficult to diagnose on plain radiographs; often the only finding is widening of the intervertebral disc space.

Delayed or occult cervical instability is defined as "instability at least 20 days after trauma, in patients who underwent sufficiently thorough $\mathrm{x}$-ray investigations during the acute phase who either did not present traumatic lesions or had only minimal lesions initially judged to be stable."24 Occult cervical instability has been described in both adult and pediatric populations, although patients younger than 25 years may be at higher risk. ${ }^{45,105}$ Because it is difficult to predict which patients will experience delayed cervical instability, some authors recommend a complete radiograph- ic and clinical reevaluation 3 weeks after injury in all patients in whom these studies are normal initially. ${ }^{45,105} \mathrm{Al}-$ though these recommendations will not always be practical, patients considered to have a high risk for delayed cervical instability include those with neurological deficits, persistent pain, microfractures, dislocations less than $3 \mathrm{~mm}$, or inversion of physiological lordosis. ${ }^{24}$

\section{Identifying SCIWORA}

Spinal cord injury without radiographic abnormality is a clinical entity primarily affecting children. In 1982, Pang and Wilberger ${ }^{72}$ defined this disorder as marked by objective signs of myelopathy resulting from trauma, with no evidence of ligamentous injury or fractures on plain x-ray films or tomographic studies. The original definition excludes penetrating trauma, electrical shock, obstetric complications, and congenital spine anomalies. Most studies of traumatic myelopathy in children report an incidence of SCIWORA greater than $20 \%,{ }^{19,40,64,80}$ and in a review of 14 series involving 617 children with traumatic myelopathy, the incidence of SCIWORA was found to be $36 \% .^{76}$ This disorder is more common in children younger than 8 years of age, and the distribution of injuries is the same as in other cervical spine injuries, with younger patients sustaining upper cervical injuries. ${ }^{39,68,70,72,76}$ Younger patients are more likely to have severe neurological injuries, ${ }^{40,68,70,106}$ and neurological deficits are often delayed. ${ }^{2,21,101}$ Factors predisposing young children to SCIWORA include a more tenuous spinal cord blood supply ${ }^{22}$ and greater elasticity in the vertebral column than in the spinal cord. ${ }^{58}$ Flexion and extension injuries are the most common mechanism, but lateral bending, distraction, rotation, axial loading, or a combination may also be involved.

The MR imaging modality is an invaluable tool for evaluating patients with SCIWORA. Findings on MR images obtained in children with this disorder can include ligamentous or disc injury, complete spinal cord transection, and spinal cord hemorrhage. ${ }^{23,39}$ Still, other patients with SCIWORA will have normal findings on MR imaging. Cases that meet the definition of SCIWORA as proposed by Pang and Wilberger ${ }^{72}$ but have a demonstrated cervical spine injury on MR imaging demonstrate that the original definition of this disorder is antiquated and should also take into account MR imaging findings along with those on plain X-ray films and CT scans.

The injuries associated with SCIWORA are generally considered stable lesions, and immobilization for up to 3 months is the recommended care..$^{70}$ Before immobilization is discontinued, stability should be confirmed using dynamic lateral radiographs. In cases of SCIWORA in which the results of dynamic studies are normal but ligamentous injury is noted on MR imaging, serial dynamic plain x-ray films should be obtained to rule out the possibility of delayed instability.

\section{Treatment Strategies}

Most pediatric cervical spine injuries can be managed nonsurgically with external immobilization., ${ }^{4,11,26,40,90}$ Even in cases of ligamentous instability, children can often heal with external immobilization and avoid surgery. ${ }^{67,86} \mathrm{Nev}-$ 
ertheless, with the development of improved surgical options for internal fixation and the frequent complications associated with halo immobilization devices, more surgeons are opting for early surgical treatment when indicated. $30,31,61$

\section{External Immobilization}

The pediatric cervical spine is more difficult to immobilize externally than adult spines because of its inherent elasticity and flexibility, and because in some cases adequate orthotic devices may not be commercially available. External immobilization of the cervical spine has two potential functions. The first and most common goal is to prevent movement and preserve cervical alignment. Second, some cases require traction to restore normal anatomical alignment.

Neonates can provide a unique challenge for immobilization because of their small body habitus. To address this difficulty, Pang and Hanley ${ }^{69}$ described a thermoplastic, molded orthotic device for the occiput, neck, and thorax. In more recent years, commercial cervical collars have started to be produced specifically for infants and children. A custom-fitted Minerva orthosis can be a reasonable alternative to a halo device in preschool-aged children, providing adequate immobilization while not interfering with activities of daily living. ${ }^{36}$ In a study of adults, a Minerva body jacket was superior to a halo immobilization device for preventing flexion and extension of each subaxial intervertebral level. ${ }^{10}$

As alluded to previously, halo devices have fallen out of favor because of the frequent complications related to their use. Children are more likely than adults to experience these complications, ${ }^{9}$ probably because of the thinner scalps and calvariae in the former group of patients. In a series of 37 patients between 3 and 16 years of age treated with a halo, $68 \%$ of the children experienced a complication related to the device. ${ }^{27}$ The most frequent complication is pin site infection, with others including pin loosening, dural or calvarial penetration, and supraorbital nerve injury., ${ }^{9,27,65} \mathrm{Ha}-$ lo devices can also inhibit activity and physiotherapy. Because of the thinner calvaria, special consideration needs to be given before placing a child in a halo device. First, more pins need to be used, with children younger than 2 years of age requiring eight to 10 pins. ${ }^{65}$ As children get older, fewer pins are required, and by the age of 4 to 5 years, only four pins are necessary. Second, the amount of torque applied to pins for fixation decreases with the patient's age. Table 1 summarizes the torque recommendations for pediatric patients.

Traction is indicated to restore cervical alignment when segmental subluxation is present. Factors that make placing a child in traction challenging include a less massive body to supply countertraction and more elastic ligaments and less musculature, which together increase the chance of overdistraction. The physician must be diligent and obtain a lateral radiograph with every change in the amount of weight used with the device, because small additions in weight can have very large effects. One pound per cervical level should be adequate in children younger than 4 years, and $2 \mathrm{lbs}$ per level is sufficient if the child is 4 years of age or older. Weight must be removed if new symptoms develop or if overdistraction is noted. For very young patients, Gardner-Wells tongs should be avoided. Instead, bilateral
TABLE 1

Torque recommendations for the halo brace in children

\begin{tabular}{cl}
\hline \hline Age (yrs) & Torque (lbs) \\
\hline $0-2$ & finger tightness \\
$2-3$ & 2 \\
$3-4$ & 3 \\
$4-5$ & 4 \\
$5-6$ & 5 \\
$\geq 6$ & $7-8$ \\
\hline
\end{tabular}

paired parietal bur holes and steel wire or a halo ring can be used. ${ }^{43}$

\section{Surgical Management}

Approximately 25 to $30 \%$ of cervical spine injuries require surgery. ${ }^{30,34}$ The goals of surgery are to improve stability of the vertebral column and to protect the spinal cord while limiting operative risks, repeated procedures, and morbidity. Indications for surgery include nonreducible deformities, unstable injuries requiring stabilization, progressive deformity, and decompression of neural structures. ${ }^{26,34}$ $54,75,82,83,90$ The chief decision for the surgeon is usually whether to perform an anterior or a posterior approach. In general, the approach should be dictated by the column that is disrupted, so that additional damage to intact structures providing stability is minimized. This point is emphasized by findings in a series of 16 patients (including some children) with posterior ligamentous disruption who were all treated with anterior fusion and in whom postoperative deformity developed ${ }^{89}$ Anterior and posterior fusions both prevent flexion, extension, and translation. A combined anterior and posterior approach is sometimes required in cases of severe disability resulting from injury to both the anterior and posterior columns.

In children, special consideration needs to be given to other issues, including the growth potential of the pediatric spine and an assessment of whether the size of the spine is adequate to accept hardware. Surgical options include posterior onlay autograft with halo placement, posterior bone and wire fusion with halo immobilization, posterior lateral mass plate instrumentation, and anterior cervical discectomy and fusion with plate and screw fixation.

By 10 years of age, the cervical spine has almost reached adult height, and thus surgery is less likely to lead to kyphosis or lordosis. ${ }^{785}$ Most of the growth potential is in the epiphysis of the VBs, with minimal potential in the posterior cervical spine. With an anterior approach, the disc and cartilaginous endplates can be removed, leading to an essentially equal ability of the anterior and posterior columns to increase in height and avoid kyphosis, even in patients younger than 10 years of age.

For children up to 4 years old, a posterior bone and cable fusion followed by external immobilization is preferred because of technical limitations of plate and screw fixation techniques in the very young. By age 5 years, anterior discectomy and fusion can be considered with an expectation of good fusion and alignment. ${ }^{16,83}$ Specialized pediatric instrumentation such as the Synthes Short Stature Anterior Cervical Spine Locking Plate is well adapted for children because of its smaller profile, decreased radius of curvature, 
and reduced screw lengths. The surgeon needs to be cognizant of the small VB remaining once the cartilaginous endplate has been removed. In patients between 5 and 10 years of age, posterior plate and screw fusion is usually avoided because of the bulk of the instrumentation, but after this age it is a reasonable alternative.

A final consideration for the surgeon is the use of autogenous bone graft or an allograft. The use of allograft should only be considered when the bone is under compression, such as with an anterior discectomy and fusion. Failure of allograft to develop solid bone union in children when used in a posterior construct has been well documented. ${ }^{54,88}$ Both rib and iliac crest are suitable for autogenous bone graft substrate..$^{57,63}$

\section{Conclusions}

Management of cervical spine trauma in children has several important differences compared with adults. The unique biomechanics of the pediatric cervical spine lead to a distinct distribution of injuries, with younger children more likely to incur upper cervical injuries and SCIWORA. Radiographic studies can also be misleading in children, with normal features such as pseudosubluxation and synchondrosis being easily mistaken for pathological findings.

Treatment of cervical spine injuries can be divided into external immobilization and surgical intervention. External immobilization with a halo device has a high incidence of complications and can be difficult because of a thin calvaria. Surgical options have improved in recent years with the development of instrumentation specifically designed for children, but special consideration must be given to the small size and growth potential of the pediatric spine.

\section{Acknowledgment}

We thank Kristin Kraus for her editorial assistance in preparing this manuscript.

\section{References}

1. Abroms IF, Bresnan MJ, Zuckerman JE, et al: Cervical cord injuries secondary to hyperextension of the head in breech presentations. Obstet Gynecol 41:369-378, 1973

2. Ahmann PA, Smith SA, Schwartz JF, et al: Spinal cord infarction due to minor trauma in children. Neurology 25:301-307, 1975

3. Allen JP, Meyers GG, Condon VR: Laceration of the spinal cord related to breech delivery. JAMA 208:1019-1022, 1969

4. Apple JS, Kirks DR, Merten DF, et al: Cervical spine fractures and dislocations in children. Pediatr Radiol 17:45-49, 1987

5. Aufdermaur M: Spinal injuries in juveniles. Necropsy findings in twelve cases. J Bone Joint Surg Br 56:513-519, 1974

6. Avellino AM, Mann FA, Grady MS, et al: The misdiagnosis of acute cervical spine injuries and fractures in infants and children: the 12-year experience of a level I pediatric and adult trauma center. Childs Nerv Syst 21:122-127, 2005

7. Bailey DK: The normal cervical spine in infants and children. Radiology 59:712-719, 1952

8. Baker DH, Berdon WE: Special trauma problems in children. Radiol Clin North Am 4:289-305, 1966

9. Baum JA, Hanley EN Jr, Pullekines J: Comparison of halo complications in adults and children. Spine 14:251-252, 1989

10. Benzel EC, Hadden TA, Saulsbery CM: A comparison of the Minerva and halo jackets for stabilization of the cervical spine. J Neurosurg 70:411-414, 1989
11. Birney TJ, Hanley EN Jr: Traumatic cervical spine injuries in childhood and adolescence. Spine 14:1277-1282, 1989

12. Bivins HG, Ford S, Bezmalinovic Z, et al: The effect of axial traction during orotracheal intubation of the trauma victim with an unstable cervical spine. Ann Emerg Med 17:25-29, 1988

13. Bohn D, Armstrong D, Becker L, et al: Cervical spine injuries in children. J Trauma 30:463-469, 1990

14. Braakman R, Penning L: The hyperflexion sprain of the cervical spine. Radiol Clin Biol 37:309-320, 1968

15. Bresnan MJ, Abroms IF: Neonatal spinal cord transection secondary to intrauterine hyperextension of the neck in breech presentation. J Pediatr 84:734-737, 1974

16. Brockmeyer D, Apfelbaum R, Tippets R, et al: Pediatric cervical spine instrumentation using screw fixation. Pediatr Neurosurg 22:147-157, 1995

17. Buhs C, Cullen M, Klein M, et al: The pediatric trauma C-spine: is the 'odontoid' view necessary? J Pediatr Surg 35:994-997, 2000

18. Burke DC: Spinal cord trauma in children. Paraplegia 9:1-14, 1971

19. Burke DC: Traumatic spinal paralysis in children. Paraplegia 11:268-276, 1974

20. Cattell HS, Filtzer DL: Pseudosubluxation and other normal variations in the cervical spine in children. A study of one hundred and sixty children. J Bone Joint Surg Am 47:1295-1309, 1965

21. Cheshire DJ: The paediatric syndrome of traumatic myelopathy without demonstrable vertebral injury. Paraplegia 15:74-85, 1977

22. Choi JU, Hoffman HJ, Hendrick EB, et al: Traumatic infarction of the spinal cord in children. J Neurosurg 65:608-610, 1986

23. Davis PC, Reisner A, Hudgins PA, et al: Spinal injuries in children: role of MR. AJNR Am J Neuroradiol 14:607-617, 1993

24. Delfini R, Dorizzi A, Facchinetti G, et al: Delayed post-traumatic cervical instability. Surg Neurol 51:588-595, 1999

25. Denis F: Spinal instability as defined by the three-column spine concept in acute spinal trauma. Clin Orthop Relat Res 189: 65-76, 1984

26. Dickman CA, Rekate HL, Sonntag VK, et al: Pediatric spinal trauma: vertebral column and spinal cord injuries in children. Pediatr Neurosci 15:237-256, 1989

27. Dormans JP, Criscitiello AA, Drummond DS, et al: Complications in children managed with immobilization in a halo vest. J Bone Joint Surg Am 77:1370-1373, 1995

28. Dula DJ: Trauma to the cervical spine. JACEP 8:504-507, 1979

29. Dwek JR, Chung CB: Radiography of cervical spine injury in children: are flexion-extension radiographs useful for acute trauma? AJR Am J Roentgenol 174:1617-1619, 2000

30. Eleraky MA, Theodore N, Adams M, et al: Pediatric cervical spine injuries: report of 102 cases and review of the literature. J Neurosurg (1 Suppl) 92:12-17, 2000

31. Evans DL, Bethem D: Cervical spine injuries in children. J Pediatr Orthop 9:563-568, 1989

32. Fesmire FM, Luten RC: The pediatric cervical spine: developmental anatomy and clinical aspects. J Emerg Med 7:133-142, 1989

33. Fielding JW, Hensinger RN: Fractures of the spine, in Rockwood CA, Wilkins KE, King RE (eds): Fractures in Children. Philadelphia: JB Lippincott, 1984, Vol 3, pp 683-730

34. Finch GD, Barnes MJ: Major cervical spine injuries in children and adolescents. J Pediatr Orthop 18:811-814, 1998

35. Flynn JM, Closkey RF, Mahboubi S, et al: Role of magnetic resonance imaging in the assessment of pediatric cervical spine injuries. J Pediatr Orthop 22:573-577, 2002

36. Gaskill SJ, Marlin AE: Custom fitted thermoplastic Minerva jackets in the treatment of cervical spine instability in preschool age children. Pediatr Neurosurg 16:35-39, 1990

37. Gaufin LM, Goodman SJ: Cervical spine injuries in infants. Problems in management. J Neurosurg 42:179-184, 1975

38. Glasauer FE, Cares HL: Traumatic paraplegia in infancy. JAMA 219:38-41, 1972 
39. Grabb PA, Pang D: Magnetic resonance imaging in the evaluation of spinal cord injury without radiographic abnormality in children. Neurosurgery 35:406-414, 1994

40. Hadley MN, Zabramski JM, Browner CM, et al: Pediatric spinal trauma. Review of 122 cases of spinal cord and vertebral column injuries. J Neurosurg 68:18-24, 1988

41. Hamilton MG, Myles ST: Pediatric spinal injury: review of 174 hospital admissions. J Neurosurg 77:700-704, 1992

42. Harris JH Jr, Edeiken-Monroe B, Kopaniky DR: A practical classification of acute cervical spine injuries. Orthop Clin North Am 17:15-30, 1986

43. Heffez DS, Ducker TB: Fractures and dislocations of the pediatric spine, in Pang D (ed): Disorders of the Pediatric Spine. New York: Raven Press, 1995, pp 517-531

44. Henrys P, Lyne ED, Lifton C, et al: Clinical review of cervical spine injuries in children. Clin Orthop Relat Res 129: 172-176, 1977

45. Herkowitz HN, Rothman RH: Subacute instability of the cervical spine. Spine 9:348-357, 1984

46. Herzenberg JE, Hensinger RN, Dedrick DK, et al: Emergency transport and positioning of young children who have an injury of the cervical spine. The standard backboard may be hazardous. J Bone Joint Surg Am 71:15-22, 1989

47. Holdsworth F: Fractures, dislocations, and fracture-dislocations of the spine. J Bone Joint Surg Am 52:1534-1551, 1970

48. Hubbard DD: Injuries of the spine in children and adolescents. Clin Orthop Relat Res 100:56-65, 1974

49. Huerta C, Griffith R, Joyce SM: Cervical spine stabilization in pediatric patients: evaluation of current techniques. Ann Emerg Med 16:1121-1126, 1987

50. Kalfas I, Wilberger J, Goldberg A, et al: Magnetic resonance imaging in acute spinal cord trauma. Neurosurgery 23:295-299, 1988

51. Keiper MD, Zimmerman RA, Bilaniuk LT: MRI in the assessment of the supportive soft tissues of the cervical spine in acute trauma in children. Neuroradiology 40:359-363, 1998

52. Kewalramani LS, Kraus JF, Sterling HM: Acute spinal-cord lesions in a pediatric population: epidemiological and clinical features. Paraplegia 18:206-219, 1980

53. Kewalramani LS, Tori JA: Spinal cord trauma in children. Neurologic patterns, radiologic features, and pathomechanics of injury. Spine 5:11-18, 1980

54. Koop SE, Winter RB, Lonstein JE: The surgical treatment of instability of the upper part of the cervical spine in children and adolescents. J Bone Joint Surg Am 66:403-411, 1984

55. Laham JL, Cotcamp DH, Gibbons PA, et al: Isolated head injuries versus multiple trauma in pediatric patients: do the same indications for cervical spine evaluation apply? Pediatr Neurosurg 21:221-226, 1994

56. Lawson JP, Ogden JA, Bucholz RW, et al: Physeal injuries of the cervical spine. J Pediatr Orthop 7:428-435, 1987

57. Lebwohl NH, Eismont FJ: Cervical spine injuries in children, in Weinstein SL (ed): The Pediatric Spine: Principles and Practice, ed 1. New York: Raven Press, 1994, pp 725-741

58. Leventhal HR: Birth injuries of the spinal cord. J Pediatr 56: 447-453, 1960

59. MacKinnon JA, Perlman M, Kirpalani H, et al: Spinal cord injury at birth: diagnostic and prognostic data in twenty-two patients. J Pediatr 122:431-437, 1993

60. Mann DC, Dodds JA: Spinal injuries in 57 patients 17 years or younger. Orthopedics 16:159-164, 1993

61. Mazur JM, Stauffer ES: Unrecognized spinal instability associated with seemingly "simple" cervical compression fractures. Spine 8:687-692, 1983

62. McPhee IB: Spinal fractures and dislocations in children and adolescents. Spine 6:533-537, 1981

63. McWhorter JM, Alexander E, Davis CH, et al: Posterior cervical fusion in children. J Neurosurg 45:211-215, 1976

64. Melzak J: Paraplegia among children. Lancet 2:45-48, 1969
65. Mubarak SJ, Camp JF, Vuletich W, et al: Halo application in the infant. J Pediatr Orthop 9:612-614, 1989

66. Nypaver M, Treloar D: Neutral cervical spine positioning in children. Ann Emerg Med 23:208-211, 1994

67. Ogden JA: Skeletal Injury in the Child, ed 2. Philadelphia: W.B. Saunders, 1990

68. Osenbach RK, Menezes AH: Spinal cord injury without radiographic abnormality in children. Pediatr Neurosci 15: 168-175, 1989

69. Pang D, Hanley EN: Special problems of spinal stabilization in children, in Cooper PR (ed): Management of Posttraumatic Spinal Instability. Park Ridge, IL: AANS, 1990, pp 181-206

70. Pang D, Pollack IF: Spinal cord injury without radiographic abnormality in children - the SCIWORA syndrome. J Trauma 29:654-664, 1989

71. Pang D, Sun PP: Pediatric vertebral column and spinal cord injuries, in Winn HR (ed): Youmans Neurological Surgery, ed 5. Philadelphia: W.B. Saunders, 2004, pp 3515-3557

72. Pang D, Wilberger JE Jr: Spinal cord injury without radiographic abnormalities in children. J Neurosurg 57:114-129, 1982

73. Panjabi MM, White AA III, Johnson RM: Cervical spine mechanics as a function of transection of components. J Biomech 8:327-336, 1975

74. Papavasiliou V: Traumatic subluxation of the cervical spine during childhood. Orthop Clin North Am 9:945-954, 1978

75. Pennecot GF, Leonard P, Peyrot Des Gachons S, et al: Traumatic ligamentous instability of the cervical spine in children. J Pediatr Orthop 4:339-345, 1984

76. Pollack IF, Pang D: Spinal cord injury without radiographic abnormality (SCIWORA), in Pang D (ed): Disorders of the Pediatric Spine. New York: Raven Press, 1995, pp 509-516

77. Ralston ME, Chung K, Barnes PD, et al: Role of flexion-extension radiographs in blunt pediatric cervical spine injury. Acad Emerg Med 8:237-245, 2001

78. Rang M: Children's Fractures, ed 1. Philadelphia: JB Lippincott, 1974

79. Roaf R: Spinal injuries. Burma Med J 8:139-143, 1960

80. Ruge JR, Sinson GP, McLone DG, et al: Pediatric spinal injury: the very young. J Neurosurg 68:25-30, 1988

81. Schleehauf K, Ross SE, Civil ID, et al: Computed tomography in the initial evaluation of the cervical spine. Ann Emerg Med 18:815-817, 1989

82. Schwarz N, Genelin F, Schwarz AF: Post-traumatic cervical kyphosis in children cannot be prevented by non-operative methods. Injury 25:173-175, 1994

83. Shacked I, Ram Z, Hadani M: The anterior cervical approach for traumatic injuries to the cervical spine in children. Clin Orthop Relat Res 292:144-150, 1993

84. Shaw M, Burnett H, Wilson A, et al: Pseudosubluxation of $\mathrm{C} 2$ on $\mathrm{C} 3$ in polytraumatized children-prevalence and significance. Clin Radiol 54:377-380, 1999

85. Sherk HH, Nicholson JT, Chung SM: Fractures of the odontoid process in young children. J Bone Joint Surg Am 60:921-924, 1978

86. Sherk HH, Schut L, Lane JM: Fractures and dislocations of the cervical spine in children. Orthop Clin North Am 7:593-604, 1976

87. Shulman ST, Madden JD, Esterly JR, et al: Transection of spinal cord. A rare obstetrical complication of cephalic delivery. Arch Dis Child 46:291-294, 1971

88. Stabler CL, Eismont FJ, Brown MD, et al: Failure of posterior cervical fusions using cadaveric bone graft in children. J Bone Joint Surg Am 67:371-375, 1985

89. Stauffer ES, Kelly EG: Fracture-dislocations of the cervical spine. Instability and recurrent deformity following treatment by anterior interbody fusion. J Bone Joint Surg Am 59:45-48, 1977

90. Stauffer ES, Mazur JM: Cervical spine injuries in children. Pediatr Ann 11:502-508, 510-511, 1982 
91. Stern WE, Rand RW: Birth injuries to the spinal cord: a report of 2 cases and review of the literature. Am J Obstet Gynecol 78:498-512, 1959

92. Sullivan CR, Bruwer AJ, Harris LE: Hypermobility of the cervical spine in children: a pitfall in the diagnosis of cervical dislocation. Am J Surg 95:636-640, 1958

93. Swischuk LE: Spine and spinal cord trauma in the battered child syndrome. Radiology 92:733-738, 1969

94. Swischuk LE, Hayden CK Jr, Sarwar M: The Dens-Arch synchondrosis versus the Hangman's fracture. Pediatr Radiol 8: 100-102, 1979

95. Swischuk LE, John SD, Hendrick EP: Is the open-mouth odontoid view necessary in children under 5 years? Pediatr Radiol 30:186-189, 2000

96. Towbin A: Latent spinal cord and brain stem injury in newborn infants. Dev Med Child Neurol 11:54-68, 1969

97. Townsend EH Jr, Rowe ML: Mobility of the upper cervical spine in health and disease. Pediatrics 10:567-574, 1952

98. Treloar DJ, Nypaver M: Angulation of the pediatric cervical spine with and without cervical collar. Pediatr Emerg Care 13:5-8, 1997

99. Viccellio P, Simon H, Pressman BD, et al: A prospective multicenter study of cervical spine injury in children. Pediatrics 108:E20, 2001

100. Vogel LC: Unique management needs of pediatric spinal cord injury patients: etiology and pathophysiology. J Spinal Cord Med 20:10-13, 1997

101. Walsh JW, Stevens DB, Young AB: Traumatic paraplegia in children without contiguous spinal fracture or dislocation. Neurosurgery 12:439-445, 1983

102. Ware ML, Gupta N, Sun PP, et al: Clinical biomechanics of the pediatric craniocervical junction and subaxial spine, in Brockmeyer DL (ed): Advanced Pediatric Craniocervical Surgery. New York: Thieme, 2005, pp 27-42

103. White AA III, Johnson RM, Panjabi MM, et al: Biomechanical analysis of clinical stability in the cervical spine. Clin Orthop Relat Res 109:85-96, 1975

104. White AA III, Panjabi MM: The problem of clinical instability in the human spine: a systematic approach, in Clinical Biomechanics of the Spine, ed 2. Philadelphia: JB Lippincott, 1990, pp 278-378

105. Wilberger JE, Maroon JC: Occult posttraumatic cervical ligamentous instability. J Spinal Disord 3:156-161, 1990

106. Yngve DA, Harris WP, Herndon WA, et al: Spinal cord injury without osseous spine fracture. J Pediatr Orthop 8:153-159, 1988

107. Zike K: Delayed neuropathy after injury to the cervical spine in children. Pediatrics 24:413-417, 1959

Manuscript received December 16, 2005.

Accepted in final form January 10, 2006.

Address reprint requests to: Douglas Brockmeyer, M.D., Department of Neurosurgery, Primary Children's Medical Center, University of Utah, 100 North Medical Drive, Salt Lake City, Utah 84113. email: douglas.brockmeyer@hsc.utah.edu. 